\title{
PATTERN OF TUBERCULOUS LYMPHADENITIS: THE ISRA UNIVERSITY HOSPITAL EXPERIENCE
}

\author{
Gul Muhammad Sheikh and Abdul Samad
}

\begin{abstract}
OBJECTIVE: To determine the commonest group and features of lymph nodes affected in tuberculous lymphadenitis at our set up.

DESIGN: A descriptive study.

SETTING: Isra University Hospital, Hyderabad over a period of three years.

Methods: The data of 180 consecutive patients visiting the outpatients department with lymph node enlargement was collected. The data was collected and analyzed with special reference to location, number and characteristics of lymph nodes involved.

RESULTS: Out of 180 patients, 151 were found to be eligible according to the selection criteria. About $81.5 \%$ of the patients had involvement of multiple lymph nodes whereas single lymph node group was involved in $\mathbf{8 4 . 8 \%}$ of the patients. Cervical group of lymph nodes was affected in about $68.9 \%$ of the patients making this group to be the commonest group affected by tuberculous lymphadenopathy. About $68.2 \%$ of the patients had matted lymph nodes whereas discrete lymph nodes were found in only $17.2 \%$ of the patients.

CONCLUSION: Multiple lymph nodes are involved in most of the patients having tuberculous lymphadenitis in our set up and in majority of the patients, only one group of lymph nodes is affected by the tuberculous lymphadenitis.
\end{abstract}

KEY WORDS: Tuberculosis. Lymph node. Location.

\section{INTRODUCTION}

Tuberculosis is one of the earliest diseases known to mankind. The mummified bodies of the Egyptians have also revealed definitive evidence of tuberculosis of bones and joints as early as 3700 B.C. Hippocrates used the term "Phthisis" for tuberculosis in 430 B.C. Phthisis is a Greek word meaning "to decay, to waste away or to shrivel up". Chinese literature also mentions the term "Loaping" for tuberculosis. Gaspard Laurent Bayp (1774-1816) has been mentioned as the person to use term "Tuberculosis" for the first time ${ }^{1}$ whereas Schonlein (1839) is also credited for the same by some researchers $^{2}$. Controversy also exists regarding the discovery of causative organism. Robert Koch (1882)

1,3 is usually considered to be the person to discover Mycobacterium Tuberculosis whereas Bolinger $(1866-1979)^{4,5}$ is also credited for the same by some researchers.

Tuberculosis is a chronic granulomatous and communicable disease caused by the organism Mycobacterium Tuberculosis. This disease usually involves the lungs but may involve the other organs and systems. The commonly involved extrapulmonary sites are lymph node, gastrointestinal tract, bone, joint, urogenital system and meninges etc.
This study looks into the commonest group as well as the characteristics of lymph nodes affected by tuberculosis in our set up.

\section{PATIENTS AND METHODS}

This descriptive study was conducted at Isra University Hospital, Hyderabad with convenient sampling strategy. The data was collected during the period between $1^{\text {st }}$ July 2001 and $30^{\text {th }}$ June 2004 . In all, 180 consecutive patients visiting the outpatients department were studied.

The selection criteria included lymph node enlargement of more than six weeks duration, shorter history of lump but strong clinical suspicion of tuberculosis, no clinical suspicion of malignancy, no focus of acute inflammation and histopathological diagnosis of non-tuberculous pathology. Every patient underwent a detailed examination with special reference to the exact location, number and characteristics of lymph nodes involved. All patients underwent histopathological examination of lymph nodes. The results were analyzed to find out the pattern of tuberculous lymphadenitis.

\section{RESULTS}

Out of 180 patients studied, 29 had non-tuberculous pathology on histopathological examination and were excluded from the study. In the final analysis of 151 patients, most of the patients had involvement of 
multiple lymph nodes whereas only 28 patients had solitary lymph node involvement. Most of the patients had only one group of lymph nodes involved whereas two or more groups of lymph nodes were found to be involved in only 23 patients. Most of the patients had unilateral lymph node involvement (Table I). Cervical lymph nodes were found to be predominantly involved (Table II). Other involved groups of lymph nodes included axillary and inguinal groups of lymph nodes. About two-third of the patients had matted lymph nodes whereas $17 \%$ of the patients were found to be having discrete lymph nodes (Table III). Some patients presented with cold abscess and few patients had discharging sinus.

\begin{tabular}{|l|c|}
\hline Involved side & Number of patients (\%) \\
\hline Right side & $72(47.7 \%)$ \\
\hline Left side & $63(41.7 \%)$ \\
\hline Bilateral & $16(10.6 \%)$ \\
\hline
\end{tabular}

TABLE I: SIDE OF THE BODY AMONG AFFECTED PATIENTS $(n=151)$

\begin{tabular}{|l|c|}
\hline Involved group & Number of patients (\%) \\
\hline Cervical & $104(68.9 \%)$ \\
\hline Axillary & $15(9.9 \%)$ \\
\hline Inguinal & $9(6 \%)$ \\
\hline Cervical + Inguinal & $6(4 \%)$ \\
\hline Axillary + Inguinal & $8(5.3 \%)$ \\
\hline Cervical+Axillary+Inguinal & $9(6 \%)$ \\
\hline
\end{tabular}

TABLE II: GROUP OF LYMPH NODES INVOLVED IN TUBERCULOUS LYMPHADENITIS PATIENTS

\begin{tabular}{|l|c|}
\hline Characteristic & Number of patients (\%) \\
\hline Discrete & $26(17.2 \%)$ \\
\hline Matted & $103(68.2 \%)$ \\
\hline Cold abscess & $19(12.6 \%)$ \\
\hline Discharging sinus & $3(2 \%)$ \\
\hline
\end{tabular}

TABLE III: CHARACTERISTICS OF LYMPH NODES INVOLVED IN TUBERCULOUS LYMPHADENITIS

\section{DISCUSSION}

Peripheral lymphadenopathy is considered as the commonest form of extra-pulmonary tuberculosis ${ }^{6,7}$. Tuberculous lymphadenitis has got a broad spectrum of presentation in the form of solitary or multiple lymph node enlargements, which may be matted or discrete and may involve any group or may present as a cold abscess or discharging sinus. This spectrum is observed in this study as well as other studies $^{8-10}$. Most of the patients in our study had matted lymph nodes and this was also seen in another study ${ }^{9}$. About $2 \%$ of the patients presented with discharging sinus and this rarity is also observed in other studies ${ }^{10}$. Cervical group of lymph nodes is considered to be the commonest site involved by tuberculous lymphadenitis. In this study, about $69 \%$ of the patients were found to be having cervical tuberculous lymphadenitis and this fact was observed in other studies as well ${ }^{11}$. The isolated axillary tuberculous lymphadenitis is relatively less common. This was found in about $10 \%$ of the patients and is consistent with findings seen in another study ${ }^{8}$. The generalized lymphadenopathy was observed as an uncommon feature of tuberculous lymphadenopathy in most of the studies ${ }^{12}$ and was seen in about $6 \%$ of the patients in this study. Other uncommon sites of tuberculous lymphadenopathy seen in various studies include mesenteric ${ }^{13}$, porta hepatis ${ }^{14,}{ }^{15}$ and retroperitoneal lymph nodes ${ }^{16}$ etc. These rare sites were not observed in this study.

\section{CONCLUSION}

On the basis of this study, we arrive at following conclusions:

1. Multiple lymph nodes are involved in most of the patients having tuberculous lymphadenitis.

2. In majority of the patients, only one group of lymph nodes is affected by the tuberculous lymphadenitis.

3. The commonest group of lymph nodes affected by tuberculosis is cervical group of lymph nodes.

4. Matting of the lymph nodes is a predominant feature of tuberculous lymphadenitis.

5. Most of the patients have unilateral tuberculous lymphadenitis in our set up.

\section{REFERENCES}

1. Rao KN. Textbook of Tuberculosis. $2^{\text {nd }}$ Ed. Vikas Publishing House Pvt. Ltd., 1981, Pp. 3-15 and 512-513.

2. Christopher D. Textbook of surgery: Disorders of lung, pleura and chest wall. $12^{\text {th }} \mathrm{Ed}$. Vol. II, WB Saunders, Philadelphia. 1981, Pp. 2093-2103.

3. Grange JM. Tuberculosis, the changing tubercle. Br J Hosp Med 1979; 22(6): 540-548.

4. Levin E, Allan A, Lucente FE. Scrofula, the dangerous masquerader. Laryngoscope 1982; 92:938-943. 
5. Alleva M, Robert AG, Thomas R. Mycobacterial cervical adenitis, a persistent diagnostic problem. Laryngoscope, 1988; 98:855-857.

6. Thompson MM, Underwood MJ, Sayers RD. Peripheral tuberculous lymphadenopathy. A review of 67 cases. Br J Surg 1992; 79(8): 763-4.

7. Majid A. Prevalence of tuberculosis in cervical lymphadenopathy. The professional 1996; 3: 223227.

8. Tariq NA. Presentation of cervical lymphadenopathy to the surgeon. Pak J Surg 1993; 9:120-123.

9. Gupta AK, Sexena RK. Bilateral retropharyngeal abscess. Pak J Otolaryngol 1992; 8:163-164.
10. Jha BC, Dass A, Nagarkar NM etal. Cervical tuberculous lymphadenopathy: changing clinical pattern and concepts in management. Postgrad Med J 2001; 77(905): 185-187.

11. Ahmed I. Primary lymphadenopathy: presentation and evaluation. Specialist 1992; 8:13-20.

12. Hanania N, Hoffstein V. Tuberculosis presenting with generalized lymphadenopathy: pulmonary infiltrates and bone destruction in a young man. Arch Intern Med 1993; 153(10): 1265-7.

13. Ahmed J and Malik ZI. Abdominal tuberculosis: The PIMS experience. J Surg 1996; 11:38-39.

14. Lafay JP, Founet $P$. Compressive abdominal tuberculous lymphadenitis of the common bile

AUTHOR AFFILIATION:
Dr. Gul Muhammad Sheikh
Department of Surgery
Isra University Hospital, Hyderabad, Sindh - Pakistan
Dr. Abdul Samad (Corresponding Author)
Assistant Professor, Department of Surgery
Isra University Hospital, Hyderabad, Sindh - Pakistan
E-mail: abdulsamad@email.com

